Tohoku J. Exp. Med., 2004, 204, 119-123

\title{
Morphine Use for At-Home Cancer Patients in Japan
}

\author{
KAZUHIKO KotANI \\ Department of Medicine, Akasaki Public Clinic, Tottori, Japan, and Division of \\ Clinical Laboratory Medicine, Faculty of Medicine, Tottori University, Yonago, \\ Japan
}

Kotani, K. Morphine Use for At-Home Cancer Patients in Japan. Tohoku J. Exp. Med., 2004, 204 (2), 119-123 — Recently, many cancer patients have been cared for at home in Japan. Cancer pain control is one of the most important factors for terminal cancer patients to maintain functional lives at home. Morphine has long been the gold standard in the control of cancer pain. This paper examined the present status of the frequency of morphine use and its prescribing route for pain control in cancer patients at home monitored by doctors offering home care medicine in Japan. We reviewed the data based on the replies to questionnaires about morphine use in a textbook edited in 2001 by the doctors supportive of home care medicine nationwide in Japan. 301 (92.9\%) among 324 doctors administered morphine for athome cancer patients. 257 doctors' replies were analyzed as to the prescribed pattern of morphine after excluding data without information on the administration route. The oral administration was most frequently used in $247(96.1 \%)$ doctors and rectal administration was used in 217 (84.4\%) doctors, while intravenous injection and epidural infusions were less common. The pattern of morphine administration was similar between doctors who worked at hospitals and clinics, except that doctors who worked at hospitals administered subcutaneously more frequently than doctors who worked at clinics (69.2\% in the hospital vs. $39.4 \%$ in the clinic setting). This study has revealed that morphine is commonly prescribed to control pain in at-home cancer patients by doctors who support home care medicine in Japan. The restricted administration routes of morphine among the doctors and less prevalent use of the subcutaneous routes in doctors who work at clinics are also shown in the home cancer care setting. These findings might result from mutual relationship between the thought and experience of doctors and clinical characteristics of patients under home care medicine. - home care; palliative care; cancer pain; administration of morphine; treatment

(C) 2004 Tohoku University Medical Press

Received March 10, 2004; revision accepted for publication July 28, 2004.

Address for reprints: Kazuhiko Kotani, M.D., Ph.D., Division of Clinical Laboratory Medicine, Faculty of Medicine, Tottori University, 86 Nishi-cho, Yonago 683-8503, Japan.

e-mail: kakotani@grape.med.tottori-u.ac.jp 
Recently medical practices including hospice care and long-term care have shifted towards home care in Japan (Kashiwagi 1991; Ikegami and Campbell 1995; Maglaveras et al. 2002). More patients who are terminally ill with diseases, such as cancer, have been cared for at home (Takahashi 1998; Ebihara et al. 2000). In the home care setting, cancer pain is one of the most frequent symptoms and problems, and pain control is one of the most important factors for terminal cancer patients who want to spend their remaining time at home. To improve the quality of life (QOL) for cancer patients, the significance of home care treatment for the relief of pain has been gradually accepted in Japan (Matoba et al. 2001). Opioids, such as morphine, have been often made available for cancer pain relief, and treatment with morphine can be performed safely for cancer patients at home, allowing patients to return to many daily social activities.

Presently, the general formulation of morphine use could be left to each doctor, and the establishment of treatment programs for at-home cancer patients that can satisfy the needs of patients and their families is required. Most recently, the transdermal therapeutic system with fentanyl (fentanyl patch) has been released in Japan, and become a useful analgesic for at-home cancer patients (Yoshizawa et al. 2003). The management of cancer pain under home care has changed, but morphine is still the main pain manager at the moment. Although it is essential to pay attention to at-home cancer patient's medication, there have been few nationwide reports concerning the situation with home care pain management in Japan. Therefore, this survey was performed to assess the actual status of pain control with morphine, just before the release of fentanyl patch, in cancer patients receiving home care among Japanese doctors offering home care medicine.

\section{Materials And Methods}

The questionnaires relating to morphine usage were sent by mail to all members of "the Japanese Society of Hospice and Home-care" and/or "the civil network of clinics supporting home care in Japan" in the year 2000. The doctors were asked about gender, age and the institution (clinic or hospital). Also the questionnaires included two main questions: (i) did you use morphine for cancer patients in home care? (ii) if the answer to (i) was "Yes," how it was administered to patients. In answering to (ii), the items of choice were prepared as "oral," "rectal," "subcutaneous," "intravenous" and "epidural" route. They were offered for self-assessment. The answers were received from 349 doctors who supported home care medicine nationwide in Japan. All replies to questionnaires were included in a textbook (Wada 2001), and we reviewed the data.

After the exclusion of ambiguous, inadequate or insufficient replies, we evaluated the application of morphine therapy to home care medicine and the route of morphine administration. Multiple responses regarding the administration route were summarized. Also, the pattern of administration of morphine was compared between the hospital and clinic settings. This comparison was assessed by chi-square analysis. Differences were considered significant at $p<0.05$. All data were treated anonymously, according to the national ethical guideline for epidemiological research in 2002.

\section{RESUlts}

We obtained available data from 324 doctors (302 men and 22 women, age: $49.6 \pm 8.3$ years (mean \pm S.D.), range: 31 to 80 years). Of these, 48 doctors (45 men and 3 women, age: $50.9 \pm 8.4$ years, range: 38 to 75 years) worked at hospitals and 276 doctors (257 men and 19 women, age: $49.4 \pm 8.3$ years, range: 31 to 80 years) worked at clinics. Twenty three doctors $(7.1 \%$; all were men, age: $48.6 \pm 10.6$ years, range: 31 to 79 years, 22 worked at clinics and one at hospital) did not administer morphine. Fourty four doctors who prescribed morphine but did not answer questions about the pattern of its administration were excluded from the following analysis. In the remaining doctors who replied on the route of mor- 
phine administration, the prescribed pattern of morphine was shown in Table1. The oral route was most frequent, the trans-rectal route was second in frequency and subcutaneous administration was sometimes observed. There were few cancer pain patients who received intravenous injection or epidural infusion of morphine.

There was a significant difference in subcutaneous administration of morphine between the hospital and clinic settings, with doctors who worked at hospitals using this approach for cancer pain more often than doctors who worked at clinics (Table 2). There were no differences in the frequencies of other routes of morphine administration between the two groups.

TABLE 1. The route of administration of morphine in at-home cancer care

\begin{tabular}{lr}
\hline Oral route & $247(96.1)$ \\
Trans-rectal route & $217(84.4)$ \\
Subcutaneous route & $113(44.0)$ \\
Intravenous route & $11(4.3)$ \\
Epidural route & $2(0.8)$ \\
\hline
\end{tabular}

257 replies were available. Multiple responses were observed. Percentages are in parentheses.

TABLE 2. The route of morphine administration in at-home cancer care between hospital and clinic settings

\begin{tabular}{lcc}
\hline \multicolumn{1}{c}{ Route } & $\begin{array}{c}\text { Hospital setting } \\
\text { (39 doctors) }\end{array}$ & $\begin{array}{c}\text { Clinic setting } \\
\text { (218 doctors) }\end{array}$ \\
\hline Oral & $39(100.0)$ & $208(95.4)$ \\
Trans-rectal & $36(92.3)$ & $181(83.0)$ \\
Subcutaneous* & $27(69.2)$ & $86(39.4)$ \\
Intravenous & $3(7.7)$ & $8(3.7)$ \\
Epidural & $0(0.0)$ & $2(0.9)$ \\
\hline
\end{tabular}

257 replies were available. Multiple responses were observed. Percentages of each group are in parentheses.

${ }^{*} p<0.05$ : hospital-setting group vs. clinic-setting group.

\section{Discussion}

We found that many doctors supportive of home care medicine took action for cancer pain control in the home care setting. In the present study, we outlined the status of morphine usage among at-home cancer patients by doctors offering home care medicine nationwide in Japan. Following various prescribing methods of morphine administration, two types, oral (e.g.; contin) and suppository administered most frequently in the home care setting, matched the widely-recognized standards in Japan (Honda and Shimizu 1994). When oral and rectal administration can not effectively manage cancer pain or is not acceptable to patients under certain circumstances, continuous subcutaneous or intravenous injection becomes necessary. To maintain consistent levels of analgesia, intravenous infusion of morphine using an infusion pump is also recommended even at home (Ebihara et al. 2000). From our findings, however, the subcutaneous or intravenous administration of morphine was infrequently carried out. And doctors who worked at hospitals more often administrated morphine using the subcutaneous method in comparison to doctors who worked at clinics. The epidural technique is wellestablished in cancer pain control (Mercadante 1999), but the control of cancer pain with an epidural block infusion of morphine was seldom used in home care. These findings might reflect mutual relationship between the thought and experience of doctors who cared for patients at home and clinical characteristics of patients who received morphine under home care, though several reasons for these can be considered including the manpower of collaborated medical professionals and institutional circumstances.

A small group of approximately $7 \%$ in surveyed doctors supportive of home care medicine answered no prescription of morphine for at-home cancer patients. The features such as gender and age in the small group were not specific for the other group. The definitive reasons for no prescription of morphine were unclear. Research on 
the regulation of morphine prescription in home care in Japan remains a future issue, coordinating with sufficient need for physicians' education of management on cancer pain at home (Adachi et al. 2004).

Our study was limited in the information and surveyed population. We could not comment on the degree to which the pain relief and QOL of patients were actually achieved and how many doses of morphine each doctor prescribed. Attitudes toward cancer by the Japanese public and doctors have changed quickly in recent years, and honesty towards cancer has become more openly discussed (Long and Long 1982; Fukaura et al. 1995; Akabayashi et al. 1999; Long 1999). Although the rate and extent of truthful disclosure regarding diagnosis, treatment and prognosis of cancer in the surveyed doctors may affect the present results, we could not ascertain it.

Palliative care, especially pain control with morphine, is very important for terminal cancer patients who prefer home care and ultimately want to die at home. We have hoped that palliative home care in Japan is more discussed and that policies and practical programs including morphine usage and alternatives to morphine (Mercadante 1999) in home cancer care are developed. In Japan, the fentanyl patch was approved and the administration had started in 2002. The fentanyl patch has been reported as an effective treatment modality for patients with cancer pain (Ahmedzai 1997; Payne 1998; Gourlay 2001; Mystakidou et al. 2002) and cancer patients under home care (Yoshizawa et al. 2003). Although the present study was performed before the widespread of the fentanyl patch, a survey including fentanyl patches and morphine will be conducted in the future.

In conclusion, morphine was commonly prescribed to control pain in at-home cancer patients by doctors supportive of home care medicine. The use of restricted administration routes of morphine among them and less prevalent use of the subcutaneous route in doctors who worked at clinics were observed in home cancer care. These findings might result from mutual relationship between the thought and experience of doctors and clinical characteristics of patients in the present home care setting in Japan.

\section{Acknowledgments}

The authors are grateful to Mr. Wakisaka, Y. for permitting us to use the data. This study was supported in part by a grant-in-aid from the Japanese Ship Building Industry Foundation, Tokyo, Japan.

\section{References}

Adachi, S., Kotani, K., Abe, M., Yamawaki, M., Shimomura, T. \& Ikawa, S. (2004) Survey on the knowledge, perception and attitude toward terminal cancer management in community medicine (in Japanese). Month. Community Med., 18, 3-12.

Ahmedzai, S. (1997) New approaches to pain control in patients with cancer. Eur. J. Cancer., 33, S8-S14.

Akabayashi, A., Kai, I., Takemura, H. \& Okazaki, H. (1999) Truth telling in the case of a pessimistic diagnosis in Japan. Lancet, 354, 1263.

Ebihara, T., Furuta, M., Kasai, H. \& Kushida, K. (2000) Role of pharmacy for home care patients. Jpn. J. Cancer Chemother., 27, 700-702. (in Japanese with English abstract)

Fukaura, A., Tazawa, H., Nakajima, H. \& Adachi, M. (1995) Do-not-resuscitate orders at a teaching hospital in Japan. N. Engl. J. Med., 333, 805-808.

Gourlay, G. K. (2001) Treatment of cancer pain with transdermal fentanyl. Lancet Oncol., 2, 165172.

Honda, K. \& Shimizu, C. (1994) Long-term pain control in terminal care with home hospice care. Jpn. J. Cancer Chemother., 21, 489-492. (in Japanese with English abstract)

Ikegami, N. \& Campbell, J.C. (1995) Medical care in Japan. N. Engl. J. Med., 333, 1295-1299.

Kashiwagi, T. (1991) Palliative care in Japan. Palliative Med., 5, 165-170.

Long, S.O. (1999) Global exchange. Family surrogacy and cancer disclosure: physician-family negotiation of an ethical dilemma in Japan. $J$. Palliative Care, 15, 31-42.

Long, S.O. \& Long, B.D. (1982) Curable cancers and fatal ulcers: attitudes toward cancer in Japan. Soc. Sci. Med., 16, 2101-2108.

Maglaveras, N., Koutkias, V., Chouvarda, I., Goulis, 
D.G., Avramides, A., Adamidis, D., Louridas, G. \& Balas, E.A. (2002) Home care delivery through the mobile telecommunications platform: the Citizen Health System (CHS) perspective. Int. J. Med. Inform., 68, 99-111.

Matoba, M., Murakami, S. \& Hoka, S. (2001) Issues in cancer pain management. Nippon Rinsho, 59, 1823-1828. (in Japanese with English abstract)

Mercadante, S. (1999) Problems of long-term spinal opioid treatment in advanced cancer patients. Pain, 79, 1-13.

Mystakidou, K., Befon, S., Tsilika, E., Dardoufas, K., Georgaki, S. \& Vlahos, L. (2002) Use of TTS fentanyl as a single opioid for cancer pain relief: a safety and efficacy clinical trial in patients naive to mild or strong opioids.
Oncology, 62, 9-16.

Payne, R. (1998) Factors influencing quality of life in cancer patients: the role of transdermal fentanyl in the management of pain. Semin. Oncol., 25, S47-S53.

Takahashi, H. (1998) Pain controls in home care patients (in Japanese). J. Jpn. Med. Assoc., 119, S338-S341.

Wada, T. (2001) Doctors' file. In: Annual List of Home Care Doctors Promoting Home Care Medicine in Japan, edited by T. Wada, Douyu-Kan Co., Tokyo, pp. 3-346. (in Japanese)

Yoshizawa, A., Gyouda, Y., Ishiguro, T., Yoshizawa, T. \& Yoshida, S. (2003) Usefulness of fentanyl patch in home palliative care. Gan To Kagaku Ryoho, 30, S129-S131. (in Japanese with English abstract) 